\title{
Conteúdo Estratégico em Organizações do Terceiro Setor: possibilidades e implicações de pesquisa no campo social
}

Augusto Cesar Marins Machado ${ }^{1}$

Sergio Bulgacov ${ }^{2}$

\section{Resumo}

A reflexão sobre temática relacionada à estratégia, seja no campo teórico ou empírico, possui forte relação com sua aplicabilidade. Entretanto, essa mesma condição aplicada às organizações do Terceiro Setor enfatiza a sua preferência por estudos que evitem a aplicação de técnicas e abordagens advindas dos estudos organizacionais. Nesse sentido, este ensaio busca fomentar as possibilidades de pesquisas e implicações do estudo do conteúdo estratégico em organizações do Terceiro Setor como reflexão e contribuição ao paradoxo disposto anteriormente, com as seguintes possibilidades empíricas: i. As possibilidades existentes nas relações interorganizacionais sobre o conteúdo estratégico e os resultados organizacionais; ii. A observação das práticas estratégicas das organizações nesse setor em suas constituições em rede; iii. As consequências das decisões sobre o conteúdo estratégico para a legitimação das práticas sociais de seus atores.

Palavras-chave: Conteúdo Estratégico. Terceiro Setor. Estudos Organizacionais.

\section{Introdução}

A atuação das organizações do Terceiro Setor no cenário das questões sociais que envolvem o país cresceu, particularmente com a redemocratização do Brasil, a partir da década de 1980, ocasionando o enfraquecimento do Estado como único agente interventor de políticas públicas e ações sociais

\footnotetext{
${ }^{1}$ Mestre em Administração pelo Programa de Mestrado em Administração da UFPR. Professor do curso de Administração da Pontifícia Universidade Católica do Paraná. Pesquisador do Observatório de Prospecção e Difusão de Iniciativas Sociais do SESI Paraná. Endereço: Universidade Federal do Paraná, Setor de Ciências Sociais Aplicadas, Departamento de Administração Geral e Aplicada, Rua Prefeito Lothário Meissner, 632 - Jardim Botânico - Curitiba-PR - Brasil. CEP: 80210-170. E-mail: machado.augustocesar@gmail.com.

${ }^{2}$ Doutor em Administração pela EASP da Fundação Getúlio Vargas. Professor e Pesquisador do Programa de Mestrado e Doutorado em Administração da UFPR. Endereço: Universidade Federal do Paraná, Setor de Ciências Sociais Aplicadas, Departamento de Administração Geral e Aplicada, Rua Prefeito Lothário Meissner, 632 - Jardim Botânico - Curitiba - PR-Brasil. CEP: 80210-170. E-mail: s.bulgacov@ufpr.br.

Artigo recebido em: 03/02/2010. Aceito em: 14/10/2010. Membro do Corpo Editorial Científico responsável pelo processo editorial: Thomas G. Brashear.
} 
(FERNANDES, 1994; FALCONER, 1999; MELO NETO; FROES, 1999; ALVES, 2000; BAVA, 2000; IBGE, 2004). Apresenta-se nessas circunstâncias, a atuação dessas organizações como elemento constituinte, agregador e complementar às ações desenvolvidas pelo Estado.

As organizações que compõem o campo social configuraram-se de diversas formas (cooperativas de catadores de lixo, creches comunitárias, institutos ou fundações empresarias de responsabilidade social, centros de capacitação), muitas até sem qualquer personalidade jurídica, na qual se fazem presentes em um contexto crítico de necessidades de recursos (físicos, materiais, humanos, financeiros); melhorias de processos de gestão (estruturas departamentais coesas e integradas; programas e projetos concisos e coerentes; instrumentos e técnicas adequadas); legitimidade (suporte contextual, prestígio com o público atendido; institucionalização de práticas e ações) (HATTEN, 1982; FALCONER, 1999).

Diante da diversidade dessas organizações, seja pela sua configuração jurídica, terminologia, formas de atuação ou propósitos diversos, essas organizações tornam-se um campo amplo e rico de investigações (SALAMON, 1997; BRESSER-PEREIRA; GRAU, 1999; FALCONER, 1999; COELHO, 2000; MORRIS, 2000; ALVES, 2002). Embora Falconer (1999) tenha considerado o Terceiro Setor no Brasil como um tema não extensivamente pesquisado, existindo ainda poucos estudos empíricos abrangentes, e um número insignificante, até recentemente com enfoque organizacional. Os primeiros esforços acadêmicos para compreender a temática do Terceiro Setor em território brasileiro surgiram somente a partir dos anos de 1990 e cada vez mais pessoas e organizações se interessam e se dedicam a estudar o assunto ou trabalhar nesse tipo de organização.

De acordo com Fischer e Mendonça (2002), informações e conhecimentos estão sendo produzidos a esse respeito, no entanto, essa produção se dá por meio de iniciativas isoladas e divergentes. Essas iniciativas geram uma falta de convergência de atividades, assim como de integração entre pesquisadores, estudiosos e militantes, além disso, há pouca divulgação dos trabalhos acadêmicos e de sua aplicação na prática das organizações.

Entre a ideologia e a politização dos discursos emblemáticos encontrados nos estudos organizacionais sobre a realidade do campo social, seja na construção de um quadro teórico próprio ou na desconstrução de propostas pautadas na lógica de mercado, aumentam as divergências e os conflitos conceituais, distanciando o foco no contexto crítico desse campo. Esse en- 
saio respeita e admite as particularidades e embates ideológicos, políticos e teóricos das distintas correntes do campo de organizações sociais, mas ressalta a importância em discutir e apresentar possibilidades e implicações de pesquisa no campo social, à luz do conteúdo estratégico em organizações do Terceiros Setor.

Além da inquietação com a necessidade de recursos, melhorias dos processos de gestão e legitimação de práticas organizacionais, de acordo com a percepção dos dirigentes dessas organizações do Terceiro Setor em relação ao contexto crítico supracitado, alguns autores (CKAGNAZAROFF, 2001; HATTEN, 1982; HUDSON, 1999; TENÓRIO, 1997; WRIGHT et al.; 2000) abordam a existência da intenção de adaptar técnicas oriundas do setor privado para o contexto das organizações do Terceiro Setor, pelo princípio de que as técnicas, em si, seriam neutras e o que importa seria o propósito pelo qual elas seriam utilizadas.

A partir dessas considerações iniciais a respeito da formação, contextualização e importância das organizações que compõem o cenário das ações sociais do Brasil, verifica-se a necessidade de resgatar o que se vem discutindo sobre esse setor emergente, como aspectos referentes à estratégia, especialmente questões envolvendo conteúdo estratégico, com o intuito de auxiliar essas organizações a terem um posicionamento mais coerente em face dos seus principais problemas.

Dessa forma, o presente ensaio busca fomentar a possibilidades de pesquisas e implicações do estudo do conteúdo estratégico em organizações do Terceiro Setor. Portanto, busca-se identificar de que forma as questões e os elementos constituintes do conteúdo estratégico podem servir de base para estudos dessas organizações.

Este estudo compactua com a premissa proposta por Anheier (2000) de que o gerenciamento das organizações não lucrativas é frequentemente mal compreendido por conta da falta de conhecimento ou suposições erradas por parte das pessoas, além de ser frequentemente mal concebido por causa das falsas suposições de como essas organizações funcionam. Logo, esse ensaio teórico torna-se fruto de diversas discussões e debates com pessoas-chave da área, bem como por meio do levantamento de fontes bibliográficas, com intuito de torná-lo mais factível e viável. 


\section{Fundamentação Teórica}

De acordo com Saunders, Lewis e Thornhill (2000), a teoria diz respeito às conexões entre fenômenos, uma história sobre por que atos, eventos, estrutura e pensamentos ocorrem. Enfatiza, ainda, a natureza das relações causais, identificando o que vem primeiro e o ritmo desses eventos. Prossegue mencionando que a teoria mergulha nos processos subjacentes, a fim de compreender as razões sistemáticas de uma ocorrência ou não ocorrência particular.

Considerando que o objeto de investigação deste ensaio - organizações do Terceiro Setor - possui campo rico e vasto de fenômenos, com relações configuradas de diversas formas, porém com literatura abrangente, que não permite plena compreensão acerca de determinados processos, verificase a necessidade em se adaptar, durante alguns momentos, conceitos advindos da literatura e trabalhos originalmente do mundo corporativo (CKAGNAZAROFF, 2001; HATTEN, 1982; HUDSON, 1999; TENÓRIO, 1997; WRIGHT et al.; 2000). Para que ideias específicas possam tornar-se mais esclarecedoras, busca-se, durante boa parte do referencial teórico, ajustar o termo empresa ou firma, trabalhadas por alguns autores, para o termo organização.

Diante da falta de dados sistematizados e da visão multifacetada - seja da estratégia ou do Terceiro Setor - verifica-se a premência de uma conexão condizente e coerente das noções teóricas, conforme mencionado por Saunders, Lewis e Thornhill (2000), a fim de que se possam verificar e validar essas noções. Nesta fundamentação teórica discorre-se sobre as principais correntes conceituais referentes ao construto conteúdo estratégico, bem como sobre o Terceiro Setor.

Sendo assim, essa fundamentação está organizada em duas seções principais. Na primeira seção, são apresentadas as discussões teóricas referentes ao conteúdo estratégico. A segunda seção apresenta e discute conceitos e terminologias do Terceiro Setor, sua origem e formação, além do conteúdo estratégico neste setor.

\subsection{Conteúdo Estratégico}

O termo estratégia vem sendo utilizado de forma indiscriminada e retratado como aspecto multifacetado ou multidimensional, o que gera interpre- 
tações e visões, de certa forma imprecisa e descuidada, por parte de alguns pesquisadores e praticantes. Essa assertiva pode ser verificada no trabalho de diversos autores (HAMBRICK, 1983; CHAFFEE, 1985; BUZZELL; GALE, 1991; MEIRELLES et al., 2000; CLEGG et al., 2004; WIPP, 2004).

Ao longo da evolução do campo da estratégia, os dois focos de interesse - acadêmico e gerencial profissional - têm sofrido interferências mútuas. Essas interferências decorrem por meio de diversas formas de análise, perspectivas e modelos teóricos sobre estratégia. Dentre esses modelos, o presente estudo busca discutir e apresentar possibilidades e implicações de pesquisa no campo social baseadas no conteúdo estratégico.

A realização de estudos nessa área é importante não somente para as organizações com fins lucrativos, mas também para organizações governamentais e não governamentais que têm um papel a ser cumprido junto à sociedade e que também devem atender com eficácia e eficiência aos propósitos para os quais foram criadas (BULGACOV et al., 2007).

Nesse sentido, o conteúdo estratégico refere-se ao posicionamento da organização em termos de produtos e mercados, dentro de contexto variável, no qual visa ao melhor desempenho organizacional. Portanto, trata-se do estudo de produtos e mercados de cada organização e os resultados dessa relação. Esses produtos visariam atender ao mercado apropriado, sob situações ambientais incertas.

Por sua vez, Ansoff (1991, p. 96) aborda o conteúdo estratégico por meio de alguns questionamentos "[...] quais produtos e tecnologias a organização irá desenvolver, onde e para quem os produtos serão vendidos e como a organização obterá vantagem sobre os concorrentes". Bulgacov (1997) prossegue também com alguns questionamentos relacionados a esse tema, como quais fatores levam à obtenção de diferentes resultados em organizações que atuam no mesmo ramo.

Em organizações baseadas em serviços, as principais características que as diferenciam dos produtos seriam a intangibilidade, a heterogeneidade ou dificuldade de padronização e a efemeridade. A literatura em estratégia tem sido ausente nesta diferenciação (HORN-SEGAL, 2003).

Outra grande contribuição dos estudos de conteúdo estratégico é apresentada por Chakravarthy e Doz (1992). Esse autores apresentam a diferenciação entre conteúdo e processo estratégico e referem-se ao conteúdo como o posicionamento da organização em face do contexto ambiental variável. 
Prosseguem mencionando que a pesquisa do conteúdo estratégico pode ser distinguida da investigação do processo estratégico em pelo menos três aspectos: enfoque, base disciplinar e metodologias. Busca-se demonstrar de forma pontual os principais aspectos que envolvem o conteúdo estratégico.

De acordo com Chakravarthy e Doz (1992), a pesquisa sobre conteúdo estratégico envolve o escopo da organização (a combinação de mercados ao qual a organização compete) e as direções de competição dentro de mercados particulares. Isso significa que esse tipo de pesquisa possui enfoque na posição efetiva da organização em face do ambiente. Mais recentemente, buscando ampliar esse enfoque, pesquisas de conteúdo estratégico têm centrado atenção na influência do acesso a recursos da organização visando o seu desempenho.

Em relação à base disciplinar que envolve a pesquisa sobre conteúdo estratégico, a pesquisa do conteúdo estratégico lida apenas, como unidade de análise, a interface da organização com o seu ambiente. Outra consideração referente a esse aspecto envolve uma quantidade reduzida de disciplinas que abarcam o conteúdo estratégico, voltadas de forma peculiar para questões ligadas à economia. Contudo, apesar de voltar-se para um fundamento disciplinar ligado à economia, não invalida a análise de questões sociais.

Por fim, ao referirem-se às metodologias que envolvem a pesquisa de conteúdo e processo estratégico, Chakravarthy e Doz (1992) enfatizam os aspectos metodológicos relacionados ao processo estratégico, citando, de forma breve, apenas a utilização de dados secundários para a realização de pesquisas do conteúdo estratégico. Porém, a utilização de procedimentos metodológicos, como questionários, surveys e observações podem ser utilizados em pesquisas de conteúdo estratégico.

Em consonância com a forma de diferenciação entre conteúdo e processo estratégico apresentado por Chakravarthy e Doz (1992), Meirelles, Gonçalves e Almeida (2000) utilizam-se desse mesmo recurso didático de análise para expandir conceito de estratégia. Vale ressaltar, conforme demonstrado na Figura 1, que esses autores relacionam o conteúdo estratégico ao mundo das ideias e abstrações, concepção diferente de como é discutida e apresentada na literatura, porém torna-se pertinente sua explanação. 


\section{ESTRATÉGIA}

\section{CONTEÚDO:}

As ideias e suas

interrelações

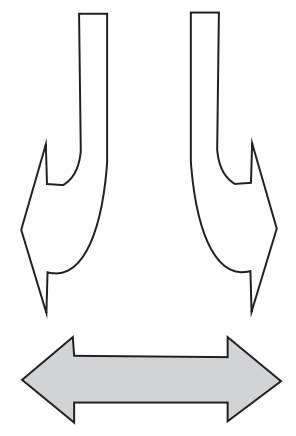

\section{PROCESSO:}

A dinâmica

envolvida na

concepção e

implantação

Figura 1: Os dois aspectos da estratégia

Fonte: Meirelles, Gonçalves e Almeida (apud ENANPAD, 2000)

Com o propósito de apresentar um modelo integrado de investigação envolvendo conteúdo, processo e resultados estratégicos, conforme Figura 2, Bulgacov e Bulgacov (2009) mencionam que os estudos que separam conteúdo e processo estratégico não explicam suficientemente a relação estrategicamente compreensível em termos de produto, mercado, ambiente e resultado.

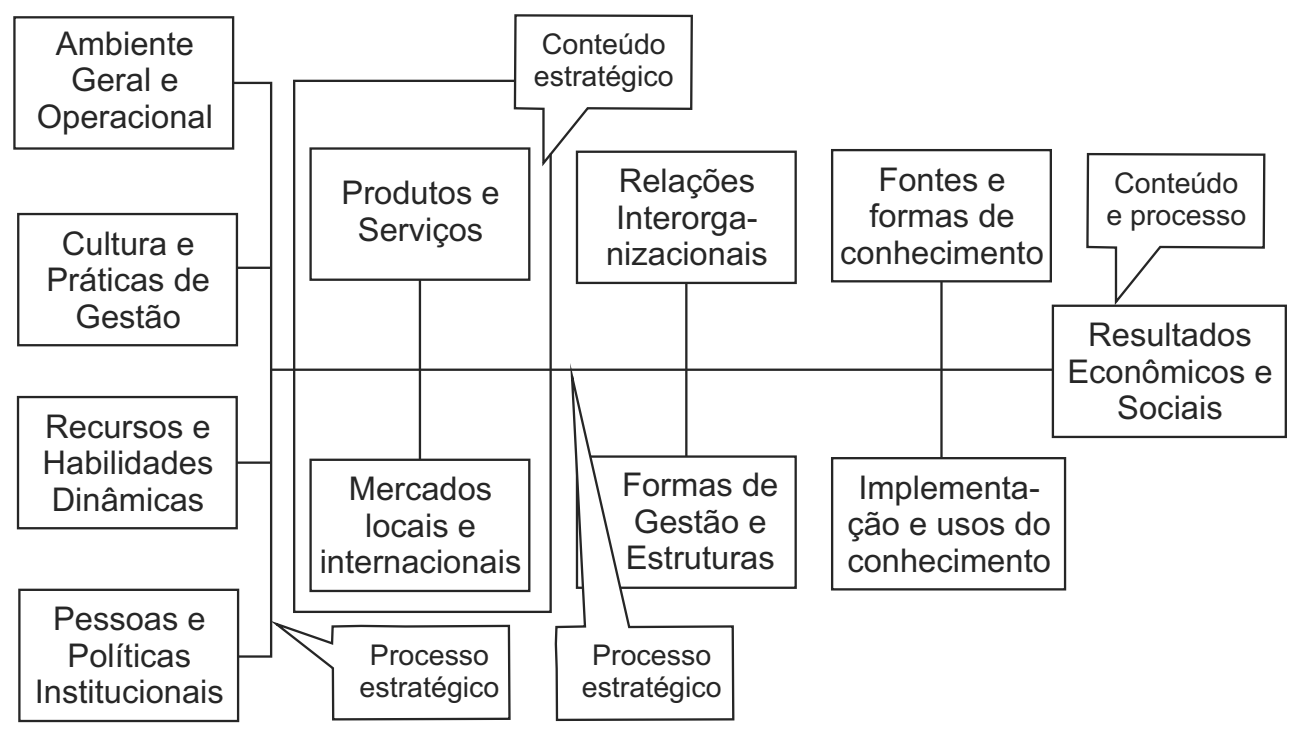

Figura 2. Conteúdo, Processo e Resultados Estratégicos Fonte: Bulgacov e Bulgacov (2009) 
O modelo proposto delineia a organização pela constituição de conteúdo e processo, e suas relações se instituem no tempo e, sobretudo, nos resultados organizacionais (BULGACOV; BULGACOV, 2009).

Outros preceitos teóricos são apresentados por Montgomery, Wernerfelt e Balakrishnan (1989) que trazem um panorama das principais pesquisas e contribuições acerca do conteúdo estratégico, bem como demonstram algumas lacunas, que ao longo do tempo, foram incorporando-se à literatura de estratégia. Eles pontuam, por meio de argumentos factíveis, alguns caminhos e direções para pesquisas futuras.

Tais autores apresentam algumas proposições científicas que servem de base para seus diagnósticos e sugestões específicas acerca da produção acadêmica sobre conteúdo estratégico: i. toda geração da teoria deve depender de algumas observações passadas; ii. todas observações devem ser guiadas e por meio de interpretação de alguma teoria; iii. uma teoria é boa se for refutável ou se for consistente com um corpo de teorias existentes.

Montgomery, Wernerfelt e Balakrishnan (1989) apontam, com base na ligação intrínseca a tais proposições apresentadas, assertivas que servem de pano de fundo para as pesquisas sobre conteúdo estratégico. A primeira assertiva indica que a teoria bem argumentada é instrumental do progresso das pesquisas de conteúdo estratégico, ou seja, pode trazer uma contribuição direta para a acumulação de conhecimento no campo. A segunda assertiva considera que a pesquisa de conteúdo estratégico progride, quando os dados são analisados de forma apurada e com suporte da teoria. Por fim, a terceira assertiva indica que, em longo prazo, a pesquisa sobre conteúdo estratégico poderá gerar recomendações proveitosas, se não for requerida em todos os artigos aplicabilidade gerencial direta, ou seja, as pesquisas referentes a essa temática poderão tornar-se mais úteis, quando possuírem caráter menos prescritivo.

A partir da concepção acerca do conteúdo estratégico apresentado por publicações seminais desse campo (CHAKRAVARTHY; DOZ, 1992; ANSOFF, 1991; BULGACOV, 1997), verificam-se como principais elementos constituintes dessa definição, os seguintes:

a) Produtos - envolve qualquer coisa que possa ser oferecida a um mercado para a devida atenção, aquisição ou consumo: objetos físicos, serviços, pessoas, lugares, organizações ou ideias (KOTLER, 1978). 
b) Mercados - grupo distinto de pessoas e/ou organizações que têm recursos que querem trocar ou que poderão concebivelmente trocar por benefícios distintos (KOTLER, 1978).

c) Contexto variável (Ambiente) - conjunto de fenômenos ou atributos externos à organização que, em constante processo de mudança, influencia, de modo potencial ou real, esta organização (HALL, 2004). Hatch (1997) apresenta outra contribuição conceitual significativa, em que considera o ambiente como o arcabouço de variáveis externas à organização, que perfazem seu contexto em nível interorganizacional, como fornecedores, interesses especiais, parceiros, competidores, clientes e agências regulatórias; e em nível de ambiente geral: legal, físico, econômico, tecnológico, social, político e cultural.

d) Desempenho organizacional ou resultado - quando o valor criado pelos bens de uma organização é, pelo menos, o mesmo valor que os proprietários esperam obter (BARNEY, 1997).

No que concerne aos estudos empíricos mais recentes sobre conteúdo estratégico, voltados ao contexto brasileiro, pode-se identificar o trabalho de Carlomagno e Almeida (2003) sobre a emergência de padrões de conteúdo e processo estratégico em três empresas gaúchas. Esses autores, a partir dos resultados analisados, perceberam que a visão do protagonista, pessoa física com participação acionária relevante em todas as empresas analisadas, influencia a geração de padrões de conteúdo e processo estratégico de forma significativa na organização.

Ainda referindo-se aos estudos empíricos, pode-se relatar a pesquisa de Hayashi Junior, Baraniuk e Bulgacov (2006), que procuraram identificar e caracterizar os principais recursos utilizados para a execução de mudanças de conteúdo estratégico em empresas de massas alimentícias. Com os dados analisados foi possível verificar a presença de um padrão consistente dos principais recursos utilizados para mudanças, dentro de cada quadrante da matriz de Ansoff (1991).

Pode-se constatar, não com o intuito de esgotar a discussão, a partir de tais concepções teóricas e estudos empíricos, a precisão da perspectiva teórica do conteúdo estratégico referente às questões que envolvem o posicionamento de uma organização em face de um contexto de imprecisão 
e incertezas ambientais. As discussões e aspectos peculiares sobre conteúdo estratégico, voltados às organizações do Terceiro Setor, serão apresentados em seção específica.

\subsection{Terceiro Setor}

\subsection{Breve Panorama}

Várias denominações são dadas - e usadas indiscriminadamente - para certo grupo de organizações que surgem por intermédio da sociedade civil: organizações sem fins lucrativos; voluntárias; não governamentais; público não estatal; economia social; setor de caridade; setor filantrópico; Terceiro Setor - termo mais usado no Brasil (ALVES, 2002; COELHO, 2000; MORRIS, 2000; BRESSER-PEREIRA, GRAU, 1999; FALCONER, 1999; SALAMON, 1997). Essas denominações variam conforme o propósito ou interesse de quem as utiliza.

Coelho (2000) afirma que ao procurar certa precisão terminológica para essas organizações, apesar de serem frequentemente utilizadas para um mesmo objeto, elas podem ter significados diferentes. No entanto, merece atenção a discussão de alguns autores sobre o termo mais usado no Brasil ou pelo menos com maior coerência aos preceitos da lógica capitalista - Terceiro Setor. Essa expressão começou a ser usada nos anos de 1970 nos EUA para identificar um setor da sociedade em que atuam organizações sem fins lucrativos, voltadas para a produção ou a distribuição de bens e serviços públicos (FERNANDES, 1994; SMITH, 1991; WEISBROD, 1988).

No Brasil, com a redemocratização do país, a partir dos anos de 1980, ocasionando o enfraquecimento do Estado como único interventor, cresce a participação e atuação das organizações que atuam no campo social. (FERNANDES, 1994; FALCONER, 1999; MELO NETO; FROES, 1999; ALVES, 2000; BAVA, 2000; IBGE, 2004). A partir dos anos de 1990 cresce a discussão e debate sobre o Terceiro Setor nas universidades brasileiras, particularmente nas escolas de Administração, com o surgimento de alguns centros de estudo como na Fundação Getúlio Vargas (Centro de Estudos do Terceiro Setor - CETS, criado em 1994) e na Universidade de São Paulo (Centro de Estudos em Administração do Terceiro Setor - CEATS, fundado em 1998). 
Diante dessas considerações acerca do surgimento do termo e do envolvimento acadêmico na discussão dessa temática, verifica-se, ainda, que a transferência crescente das políticas sociais para o poder local (qualquer comunidade ou grupos sociais organizados de forma associativa), ou seja, a articulação da sociedade civil em torno de organizações que representam os seus anseios e interesses; a institucionalização de alguns movimentos sociais; o investimento dos organismos internacionais, órgãos multilaterais, bilaterais, entre outros, em projetos e iniciativas promovidas no âmbito da sociedade civil, configuram-se em um cenário no qual o Terceiro Setor emergiu como alternativa viável para os problemas sociais.

De acordo com esse cenário, é possível constatar que a emergência das organizações que compõem o campo social representam, em tese, uma mudança de orientação no Brasil no que diz respeito ao papel do Estado e do Mercado e, em particular, à forma de participação do cidadão na esfera pública. Isso tem levado à aceitação crescente da ampliação do conceito de público como não exclusivamente sinônimo de estatal: "público não estatal" (FALCONER, 1999).

Não obstante, a relevância das organizações no campo social, a lacuna de bases de dados representativas à realidade dessa área dificultam a atuação de pesquisadores e gestores em definirem ações condizentes aos principais problemas ou necessidades da sociedade. A convergência, o monitoramento e a manutenção de informações sobre o campo social possibilitam a formação de redes sociais e alianças interorganizações ou a identificação das estratégias construídas por meio das interações entre funcionários, público atendido e colaboradores.

As variações terminológicas, a falta de dados sistematizados, assim como a grande gama de papéis que desempenham, tornam as organizações do Terceiro Setor difíceis de serem identificadas em cada lugar. De acordo com Salamon (1998), os sérios problemas de definição conceitual se juntam com o variado tratamento jurídico que essas organizações recebem nas estruturas legais brasileiras, além de barreiras ideológicas que também obscurecem a identificação do papel e da escala real dessas organizações.

\subsubsection{Conteúdo Estratégico no Terceiro Setor}

Conforme exposto em seção sobre conteúdo estratégico, demonstrado de forma abrangente, o principal foco das investigações que envolvem essa 
temática está no efetivo posicionamento da organização em relação ao seu ambiente, além da questão do acesso aos recursos da organização e do seu desempenho ou resultado. Nesta seção busca-se apresentar alguns aspectos e discussões tratados na literatura de forma subjacente, pelo fato de se esbarrar em uma produção acadêmica ainda incipiente sobre os principais elementos que compõem o conteúdo estratégico das organizações do Terceiro Setor.

Para Hatten (1982), a identificação, avaliação e reformulação da estratégia para a organização não lucrativa decorre da adaptação desenvolvida dos preceitos concernentes à administração estratégica corporativa. Essa autora considera a administração estratégica como o processo que determina e mantém um conjunto viável de relações entre a organização e o ambiente. Por sua vez, esse conjunto de relações pode ser considerado como indicativo ligado a um dos elementos constitutivos do conteúdo estratégico: contexto variável.

O conteúdo estratégico em organizações do Terceiro Setor, apesar de poder apresentar diferentes costumes e práticas, ou formas estruturais e conjunturais distintas, geralmente aborda os seguintes elementos.

a) De acordo com a definição de Kotler (1978), demonstrado em seção precedente sobre conteúdo estratégico, os produtos considerados em organizações do Terceiro Setor se constituem por meio de serviços. Esses serviços, por sua vez, podem ser verificados particularmente nos programas e projetos que esse tipo de organização desenvolve.

- Programas e Projetos: Consistem em intervenções sistemáticas, planejadas com o objetivo de atingir uma mudança na realidade social (CANO, 2002).

b) O contexto variável ou o ambiente das organizações sociais podem ser considerados todos os relacionamentos que elas desenvolvem e que influenciam os outros elementos constituintes do seu conteúdo estratégico.

c) Os mercados de uma organização social referem-se, particularmente neste estudo, ao público atendido, bem como a organizações congêneres, organização com as quais se relacionam: enfim, seus stakeholders. 
d) Os resultados podem ser definidos de forma mais apurada para as organizações sociais, como sendo os resultados alcançados, o valor obtido para o público-alvo da organização, bem como para seus stakeholders de forma geral. Esses resultados serão objeto de investigação se forem provenientes da relação entre serviços e públicos atendidos ou stakeholders. Tais elementos podem ser visualizados conforme Figura 3:

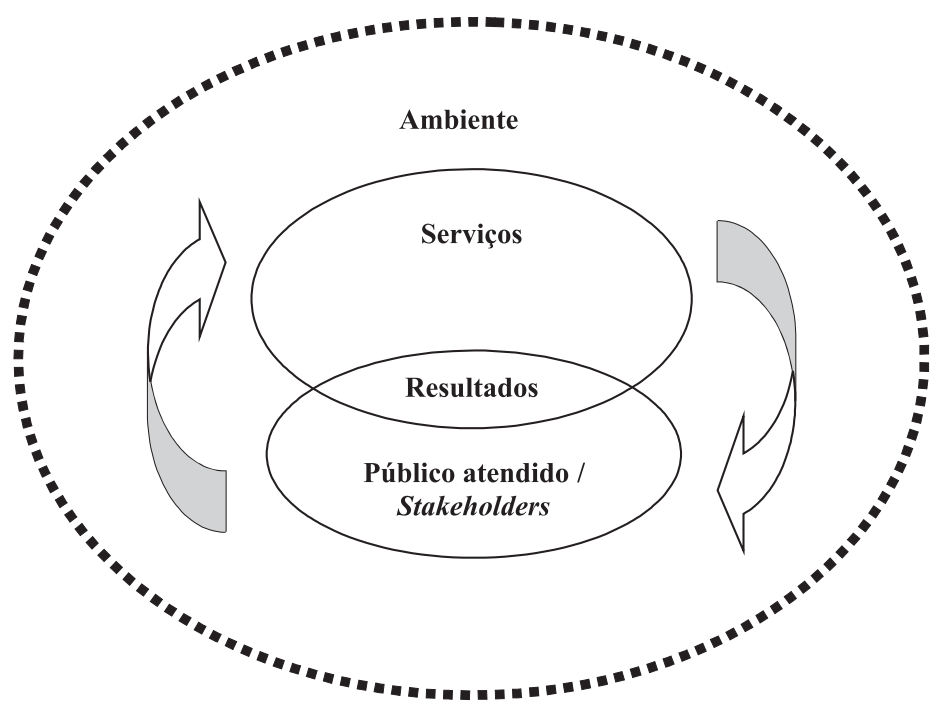

Figura 3: Elementos do Conteúdo Estratégico em Organizações do Terceiro Setor Fonte: Machado (2008)

Além da transposição de Hatten (1982) sobre estratégia para o mundo das organizações sociais, Hudson (1999) considera que a estratégia é particularmente importante nas organizações orientadas por valores, organizações do Terceiro Setor, porque existem sempre coalizões de pessoas com aspirações diferentes, que precisam ser integradas para que a organização progrida.

A formalização ou concepção clara do conteúdo estratégico com todos os procedimentos internos registrados, organizados e documentados, de forma digital ou não, auxiliam os indivíduos, que compõem as organizações neste campo, a terem noção mais precisa das necessidades dessas entidades e, por conseguinte, a minimização das coalizões das pessoas com aspirações diferentes. 
Segundo Hudson (1999), para o Terceiro Setor, a necessidade de explicitar a missão da organização torna-se uma prioridade, já que cabe à organização esclarecer ao financiador e aos demais participantes o que está sendo realizado com os recursos por eles disponibilizados. Pode-se constatar que o conjunto de elementos que constituem o conteúdo estratégico de uma organização do Terceiro Setor se faz presente na sua missão: propósito organizacional.

Diante dessas questões, Hudson (1999) aponta alguns dilemas estratégicos em que as organizações se encontram. Dentre eles se deparam: uma pequena ajuda para muitos ou uma grande ajuda para poucos; tratar os sintomas ou a causa; fornecer serviços ou realizar campanhas por mudanças; concentrar ou diversificar os serviços; manter-se fiel às crenças ou ser atraído por novos recursos. Tanto as reflexões como os dilemas geram alguns desafios.

Seguindo outra linha de pensamento, Salamon (1997) menciona que alguns desafios são defrontados para que o Terceiro Setor possa passar de um estágio emergente ou de emergência e se transforme em realidade efetiva e consistente. Os principais desafios seriam de legitimidade, eficiência, sustentabilidade e colaboração.

Em face da escassez de informações precisas acerca de estudos teóricos ou empíricos sobre conteúdo estratégico em organizações do Terceiro Setor, ressalta-se a importância deste ensaio para gerar caminhos concretos e fontes fidedignas que possam conhecer melhor este assunto nessas organizações.

\section{Conclusões}

Ao fomentar a discussão, a reflexão e a busca de informações pormenorizadas acerca da realidade das organizações do Terceiro Setor, a construção teórico-epistemológica do objeto fundamental de investigação deste ensaio teórico procurou manter-se consistente e em uma sequência lógica aos ditames delineados pelos principais autores da área de organizações e estratégia.

No contexto da ausência de trabalhos seminais no campo dos estudos organizacionais e de estratégia, em destaque o seu início a partir dos anos de 1980, verifica-se também quantidade significativa de opiniões e posições divergentes e conflitantes, além de posições epistemológicas radicais e contrárias à inclusão dos estudos organizações na perspectiva do Terceiro Setor. A excessiva ideologização e politização imersa nos estudos sobre organiza- 
ções sociais escamoteiam os preceitos dos estudos de estratégia em mesmo nível dos aspectos políticos e ideológicos, principalmente diante da realidade de necessidade de recursos e a imersão dessas organizações na esfera da economia, da política e da sociedade real e contemporânea.

Outros obstáculos que surgem ao pleno êxito de estudo dessas organizações é a falta de credibilidade de algumas instituições representativas que podem, de alguma forma, disponibilizar dados que possam ser utilizados e analisados por pesquisadores interessados neste campo. A dispersão ou escassez dos dados caracterizam-se também como mais uma barreira aos estudos na área.

Além disso, por se tratar de tema eminentemente exploratório, algumas obstruções de natureza metodológica também poderão ser constatadas, como a dificuldade de coleta dos dados e a própria interpretação de pesquisadores, que conduzem cuidados e prudência em face de certas conclusões dos estudos que são desenvolvidos. No entanto, além desses obstáculos mencionados e diante do contexto crítico de necessidades de recursos, melhorias de processos de gestão e estabelecimento de legitimidade (HATTEN, 1982; FALCONER, 1999), tornou-se relevante este estudo pelo fato primordial de trazer a ótica organizacional para uma área do Terceiro Setor de forte predominância ideológica.

Assim, podem ser identificadas como principais contribuições práticas para as organizações do Terceiro Setor: i. melhoria da compreensão das ações de conteúdo estratégico, através da identificação dos atores que mantêm relações interorganizacionais significativas com as entidades sociais; ii. reconhecimento dos principais aspectos condicionantes para a manutenção das ações de conteúdo estratégico; iii. otimização de resultados oriundos da dinâmica dos processos relacionados ao conteúdo estratégico das entidades sociais.

A melhoria da compreensão das ações de conteúdo estratégico, através da identificação dos atores que mantêm relações interorganizacionais significativas com as entidades sociais, pode ser útil para que essas entidades desenvolvam ações centradas nas competências centrais de cada um dos parceiros.

O reconhecimento dos principais aspectos condicionantes para a manutenção das ações de conteúdo estratégico pode ser útil para que as organizações do Terceiro Setor possam direcionar suas prioridades em relação ao desenvolvimento e manutenção das parcerias e mensurá-los, para que os dirigentes dessas entidades tenham maior controle das variáveis que permeiam o conteúdo estratégico e os resultados. 
A otimização de resultados obtidos, oriundos de processos de mudança de conteúdo estratégico das entidades sociais pode ser vantajoso para essas entidades, a partir da caracterização desses resultados que podem servir como instrumento de minimização das falhas e maximização de oportunidades para o desenvolvimento do conteúdo estratégico.

A realização deste ensaio teórico não possui caráter conclusivo, no sentido de esgotar o tema; apenas proporciona alguns questionamentos e reflexões que podem gerar estudos futuros. Então, seguem como sugestões os seguintes trabalhos:

a) Realização de estudo comparativo com organizações do Terceiro Setor.

b) Estudo longitudinal dos aspectos condicionantes de conteúdo estratégico das organizações do Terceiro Setor.

c) Análise da percepção dos atores envolvidos no estabelecimento de relações interorganizacionais com organizações do Terceiro Setor sobre o conteúdo estratégico e sobre os resultados dessas entidades.

d) Verificação da influência da formação de redes na prática estratégica das organizações do Terceiro Setor.

e) Análise da percepção do impacto do conteúdo estratégico pelos participantes envolvidos nas relações interorganizacionais das organizações do Terceiro Setor.

\section{Strategic Content in Third Sector Organizations: possibilities and implications of social research in the field}

\section{Abstract}

The reflection on themes related to strategy, either in theoretical or empirical, has strong relationship with its applicability. However, this condition applied to Third Sector organizations emphasizes his preference for studies that avoid the application techniques and approaches developed on organizational studies. Thus, this paper 
seeks to promote the research possibilities and study of strategic content implications on third sector organizations such as reflection and contribution to the paradox presented above, with the following empirical possibilities: i. The possibilities present on interorganizational relations at strategic content framework and organizational outcomes; ii. The observation of strategic practices of organizations in this sector and their social network constitutions; and iii. The consequences of decisions at the strategic content to legitimize the actors social practices.

Key words: Strategic Content. Third Sector. Organizational Studies.

\section{Referências}

ALVES, F. de Assis. Fundações, organizações sociais, agências executivas: organizações da sociedade civil de interesse público e demais modalidades de prestação de serviços públicos. São Paulo: LTr, 2000.

ALVES, M. A. Terceiro Setor: as origens do conceito. In: ENCONTRO NACIONAL DA ASSOCIAÇÃO DOS PROGRAMAS DE PÓS-GRADUAÇÃO EM ADMINISTRAÇÃO, 26, 2002, Salvador. Anais...Salvador: ANPAD, 2002.1 CD-ROM.

ANHEIER, H. K. Managing non-profit organisations: toward a new approach. Civil Society Working Paper 1. January, 2000.

ANSOFF, I. A nova estratégia empresarial. São Paulo, Atlas, 1991.

BARNEY, J. Gaining and sustaining competitive advantage. New York: Addison-Wesley Publishing Company, 1997.

BAVA, S. C. ONGs: Identidade e desafios atuais. São Paulo: Cadernos ABONG n. 27, 2000.

BRESSER-PEREIRA, L. C.; GRAU, N. C. Entre o Estado e o Mercado: o Público Não-Estatal. In: BRESSER-PEREIRA, L. C.; NURIA, Cunill Grau (Orgs.)

O Público Não-Estatal na Reforma do Estado. Rio de Janeiro: Editora FGV, 1999: 15-48.

BULGACOV, S. Conteúdo e Processo Estratégico: estudo comparativo de casos na indústria alimentícia do Paraná. São Paulo, 1997 - Tese de Doutorado. Escola de Administração de Empresas/FGV. 
BULGACOV, S. et al. Administração estratégica: teoria e prática. São Paulo: Atlas, 2007.

BUlGACOV, S.; BULGACOV, Y. L.M. Conteúdo e Processo Estratégico: Formação, Implementação e Resultados. In: ENCONTRO DE ESTUDOS EM ESTRATÉGIA, 4, 2009, Recife. Anais... Recife: ANPAD, 2009. CD-ROM.

BUZZELL, R. D.; GALE, B. T. O impacto das estratégias de mercado no resultado das empresas. São Paulo: Livraria Pioneira, 1991.

CANO, I. Introdução à avaliação de programas sociais. Rio de Janeiro: FGV, 2002.

CARLOMAGNO, M. S.; ALMEIDA, S. O. Estratégia: emergência de padrões de conteúdo e processo de formação em três empresas gaúchas. In: ENCONTRO NACIONAL DA ASSOCIAÇÃO DOS PROGRAMAS DE PÓS-GRADUAÇÃO EM ADMINISTRAÇÃO, 27, 2003, Atibaia. Anais...Atibaia: ANPAD, 2003.1 CD-ROM.

CHAFFEE, E. E. Three models of strategy. Academy of Management Review, v. 10, n.1, 1985.

CHAKRAVARTHY, B. S.; DOZ, Y. Strategy Process Research: Focusing on Corporate Self-Renewal. London: Strategy Management Journal, 1992, v. 13 special issue, p. 5-14.

CKAGNAZAROFF, I. B. Desafios da gestão em organizações do Terceiro Setor. In: PIMENTA, S. M.; CÔRREA, M. L. (Orgs.). Gestão, trabalho e cidadania: novas articulações. Belo Horizonte: Autêntica/CEPEAD/FACE/UFMG, 2001.

CLEGG, S.; CARTER, C.; KORNBERGER, M. A "máquina estratégica": fundamentos epistemológicos e desenvolvimentos em curso. Revista de Administração de Empresas, v. 44, n. 4, 2004.

COELHO, S. C. T. Terceiro setor: um estudo comparado entre Brasil e Estados Unidos. São Paulo: Editora SENAC São Paulo, 2000.

FALCONER, A. A promessa do Terceiro Setor: um estudo sobre a construção do papel das organizações sem fins lucrativos e do seu campo de gestão. Tese de Doutorado apresentada a Universidade de São Paulo. 1999. 
FERNANDES, R.C. Privado, porém público: o terceiro setor na América Latina. Rio de Janeiro: Relume-Dumará, 1994.

FISCHER, R. M.; MENDONÇA, L. R. Transforming Civil Society, Citizenship and Governance: The Third Sector in an Era of Global (Dis)Order. ISTR Fifth International Conference Cape Town, South Africa / July 7-10, 2002

HALL, Richard H. Organizações: estruturas, processos e resultados. São Paulo: Prentice Hall, 2004.

HAMBRICK, D. C. Some tests of the effectiveness and functional attributes of miles and snow's strategic types. Academy of Management Journal, v. 26, n. 1, p. 5-26, 1983.

$\mathrm{HATCH}, \mathrm{M}$. J. Organization theory: modern symbolic and postmodern perspectives. New York: Oxford University Press, 1997.

HATTEN, M. L. Strategic Management in Not-For-Profit Organizations.

Strategic Management Journal, v. 3,p. 89-104, 1982.

HAYASHI JUNIOR, P.; BARANIUK, J. A.; BULGACOV, S. Mudanças de Conteúdo Estratégico em pequenas empresas de massas alimentícias. Revista de Administração Contemporânea. Rio de Janeiro: v.10, n. 3, 2006.

HUDSON, M. Administrando Organizações do Terceiro Setor. São Paulo: Makron Books, 1999.

IBGE. As Fundações Privadas e Associações sem fins lucrativos no Brasil 2002. Rio de Janeiro: IBGE, 2004.

KOTLER, P. Marketing para organizações que não visam o lucro. São Paulo: Atlas, 1978.

MEIRELlES, A. M.; GONÇALVES, C. A.; ALMEIDA, A. F. Uma abordagem para estratégia utilizando analogias. In: ENCONTRO NACIONAL DA ASSOCIAÇÃO DOS PROGRAMAS DE PÓS-GRADUAÇÃO EM ADMINISTRAÇÃO, 24, 2000. Florianópolis. Anais... Florianópolis: ANPAD, 2000.1 CD-ROM.

MELO NETO, F. P.; FROES, C. Responsabilidade social e cidadania empresarial: a administração do terceiro setor. Rio de Janeiro. Qualitymark, 1999. 
MONTGOMERY, C. A.; WERNERFELT, B.; BALAKRISHNAN, S. Strategy Content And The Research Process: A Critique And Commentary. Strategic Management Journal, v. 10, p. 189-197, 1989.

MORRIS, S. Defining the non-profit sector: Some lessons from history. Civil Society Working Paper 3. Center for civil society, London Scholl of Economics. Also in Voluntas, 2000.

SALAMON, L. M. A emergência do Terceiro Setor - uma revolução associativa global. Revista de Administração USP, v. 33, n. 1, jan./mar. 1998.

SALAMON, L. M. Estratégias para o fortalecimento do Terceiro Setor. In: IOSCHPE, Evelyn (et al.). $3^{\circ}$ Setor: desenvolvimento social sustentado. Rio de Janeiro: Paz e Terra, 1997.

SAUNDERS, M.; LEWIS, P.; THORNHILL, A. Research methods for business students. Harlow, England: Pearson Education, 2000.

SMITH, D. H. Four Sectors or Five? Retaining the Member-Benefit Sector. Nonprofit and Voluntary Sector Quarterly, v. 20, n. 2, Summer 1991, p. 137-50.

TENÓRIO, F. G. Gestão de ONG's: principais funções gerenciais. Rio de Janeiro: Fundação Getúlio Vargas, 1997.

WEISBROD, B. Nonprofit Economy. Cambridge: Harvard University Press, 1988.

WIPP, R. Desconstrução criativa: estratégia e organizações. In: CALDAS, M.; FACHIN, R.; FISCHER,T. (Org.). Handbook de Estudos Organizacionais: Modelos de Análise e Novas Questões em Estudos Organizacionais. 1. ed, v.3. São Paulo: Atlas, 2004.

WRIGHT, Peter L. et al. Administração Estratégica: conceitos. São Paulo: Atlas, 2000. 